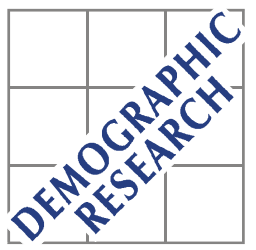

Demographic Research a free, expedited, online journal of peer-reviewed research and commentary in the population sciences published by the Max Planck Institute for Demographic Research Konrad-Zuse Str. 1, D-18057 Rostock · GERMANY www.demographic-research.org

DEMOGRAPHIC RESEARCH

VOLUME 24, ARTICLE 15, PAGES 345-374

PUBLISHED 22 FEBRUARY 2011

http://www.demographic-research.org/Volumes/Vol24/15/

DOI: 10.4054/DemRes.2011.24.15

Research Article

Exploring the meaning of context for health:

Community influences on child health

in South India

Nancy Luke

Hongwei Xu

(C) 2011 Nancy Luke \& Hongwei Xu.

This open-access work is published under the terms of the Creative Commons Attribution NonCommercial License 2.0 Germany, which permits use, reproduction \& distribution in any medium for non-commercial purposes, provided the original author(s) and source are given credit.

See http:// creativecommons.org/licenses/by-nc/2.0/de/ 


\section{Table of Contents}

$\begin{array}{lll}1 & \text { Introduction } & 346\end{array}$

2 The setting and methodological challenges 348

$3 \quad$ Previous research on the correlates of child health 351

3.1 Community-level effects 351

3.2 Individual- and family-level effects 352

$4 \quad$ Data and methods $\quad 353$

4.1 Dependent variables 354

$\begin{array}{ll}4.2 & 355\end{array}$

$\begin{array}{lll}4.3 & \text { Analytical strategy } & 357\end{array}$

$5 \quad$ Results $\quad 359$

6 Discussion and conclusions 362

$7 \quad$ Acknowledgements $\quad 366$

$\begin{array}{ll}\text { References } & 367\end{array}$ 


\title{
Exploring the meaning of context for health: Community influences on child health in South India
}

\author{
Nancy Luke ${ }^{1}$ \\ Hongwei $\mathrm{Xu}^{2}$
}

\begin{abstract}
Much research attention has been devoted to community context and health. Communities are often defined as residential spaces, such as neighborhoods, or as social groupings, such as caste in India. Using data from a group of tea estates in South India, we attempt to address important methodological challenges in the identification of neighborhood effects on child health. We find significant neighborhood effects for weight for age at age one, including a protective role for community-level women's education, but none for birth weight. In contrast to the usual pattern in rural India, caste disparities in child health are also eliminated in this setting.
\end{abstract}

\footnotetext{
${ }^{1}$ Corresponding author. Department of Sociology, Faculty Affiliate, Population Studies and Training Center, Brown University, Box 1916, Providence, RI 02912 USA, Tel: 401-863-2243. Fax: 401-863-3213.

E-mail: Nancy_Luke@brown.edu.

2 Population Studies and Training Center, Brown University, Box 1916, Providence, RI 02912 USA. E-mail: hongwei.p.xu@gmail.com.
} 


\section{Introduction}

A great deal of research attention has been devoted to the connection between community context and health. A large body of work concerns neighborhood effects, which views community as a geographically defined space in which individuals reside and interact. Residential communities have been variously defined in the literature, including by census tracks, zip code areas, villages, districts, or regions of countries (e.g., Browning and Cagney 2002; Wen, Cagney, and Christakis 2005; Kandala, Magadi, and Madise 2006; Shin 2007; Linnemayr, Alderman, and Ka 2008). This work recognizes that the ideas and behavior of people living in close proximity can affect health outcomes independent of individual characteristics (Sampson, Raudenbush, and Earls 1997). Much of the recent theoretical and empirical research on neighborhood effects is based in urban areas in the United States, where the neighborhood is a prominent social unit (e.g., Sampson, Raudenbush, and Earls 1997; Malmstrom, Sundquist, and Johansson 1999; Sampson, Morenoff, and Gannon-Rowley 2002; Wen, Cagney, and Christakis 2005; Cohen et al. 2006).

Community affiliations can also be defined in relational terms, where individuals are categorized according to shared histories, identities, and interests regardless of space or residential patterns (Cornish and Ghosh 2007; Abbott and Luke forthcoming). These relational types of community include race, ethnicity, and the kinship group or clan, and a wealth of research has examined health disparities across these social groupings. These studies share their theoretical underpinnings with those of neighborhood effects research, and contend that social interactions between group members can influence health behaviors and outcomes, regardless of individual attributes. In India, the endogamous sub-caste, or jati, continues to be the major locus of social contact and source of social and economic support for most individuals, even though sub-caste groups are often spread over large areas, such as an entire Indian state (Munshi and Rosenzweig 2009). The caste hierarchy was based on traditional occupations assigned across sub-castes, with the lowest caste groups undertaking the most menial and ritually polluting tasks (Milner 1994). These historical divisions form the basis of persistent symbolic and material inequalities today, including poorer maternal and child health outcomes among the lower castes (Pal 1999; Bonu, Ramin, and Baker 2003; Som et al. 2006; Dommaraju, Agadjanian, and Yabiku 2008).

In many settings worldwide, community affiliations intersect. For example, neighborhoods in urban America are often segregated to a large extent by race and ethnicity. In rural areas of India, sub-castes usually reside in separate streets or hamlets within the village, and the lowest castes are often relegated to land on the village outskirts (Kapadia 1995; Navaneetham and Dharmalingam 2002). In these contexts of strong correlation between the neighborhood and the race or caste, it is difficult to 
attribute observed effects to either type of community (Rosenzweig and Wolpin 1986; Oakes 2004; Subramanian 2004; Acevedo-Garcia and Osypuk 2008).

Identifying the influential domains of social interaction-the caste, the neighborhood, or both - and the processes by which they affect health could help eliminate the underlying causes of disparities in India. Therefore, an interesting question is whether, if caste groups were residentially integrated, neighborhood effects would arise that could affect health outcomes. Caste groups are likely to be more residentially intermixed in urban areas, where the development of neighborhood effects could be examined. Nevertheless, research on neighborhood effects in urban India must confront the same problems as studies conducted in urban America: namely, the selfselection of individuals into neighborhoods and the possibility that the neighborhood proxies for unobserved individual characteristics that are correlated at the level of the community, such as wealth or access to health information and services (Sampson, Raudenbush, and Earls 1997; Yen and Syme 1999).

In this study, we attempt to isolate neighborhood effects on birth weight and child nutritional status in India, and explore the pathways by which these types of community effects could operate. We use data from a unique setting in South India, which allows us to gain leverage on several of the challenging methodological issues related to community effects research. We conducted our study in a group of tea plantations, or estates, all of which belong to the same tea company. On the estates, selection into residential units is fundamentally pre-determined and fixed, and numerous caste groups have lived and worked alongside each other in estate divisions, which we treat as the neighborhood, for over three generations. The structure of the tea estates provides additional benefits that permit us to isolate local social processes, including the provision of equal economic opportunities and standardized access to health and welfare services across households, neighborhoods (divisions), and castes. Thus, in this special research setting, caste groups have been integrated historically and important structural factors are controlled for, which makes it an ideal testing ground for exploring whether and how neighborhood social processes could affect child health in India.

The paper is organized as follows. The next section describes the tea estates setting in greater detail and the methodological issues we attempt to address. Section 3 provides a brief review of previous research on the correlates of birth weight and child nutritional status at the community, individual, and family levels. Section 4 describes the survey data, the construction of variables, and our multi-level random effects analytical strategy. The results are presented in Section 5, and the final section concludes. 


\section{The setting and methodological challenges}

The tea estates lie in the High Range, a mountainous area straddling the modern Indian states of Kerala and Tamil Nadu. British planters converted the previously uninhabited forest land into plantations in the 1860s, and contract workers migrated to the estates from the plains of Tamil Nadu. Many of these individuals belonged to agrestic slave castes who served as indentured workers to their landowners in Tamil Nadu. The slave castes were officially emancipated by the British colonial government in 1861 (Hjejle 1967), although employment opportunities in the tea estates attracted workers from other castes as well. Workers were made permanent employees in the 1930s, at which time their families joined them, and they were assigned employment and housing across multiple divisions in each estate. Each division has approximately 100 families, and is equivalent to a small neighborhood. Caste groups are distributed across divisions, and no division consists of only one caste. Because company rules prevent workers from transferring across divisions, or new workers from entering the estates, except through marriage, most of the current workers are the third-generation descendents of the original migrant families from the 1930s. While the distinctive structural characteristics of the tea estates are not typical of a rural South Indian village, this research setting is nevertheless well-suited to address some of the methodological difficulties that confront the study of community effects and health outcomes.

First, a study of workers on the tea estates provides the opportunity to explore community effects at the local level, where daily social interactions take place. There is emerging work on community effects on health in India, which generally focuses on the level of the state, district, or cluster of villages of residence (Griffiths, Matthews, and Hinde 2002; Stephenson and Tsui 2002; Kravdal 2004; Parashar 2005; Dommaraju, Agadjanian, and Yabiku 2008). This research uses large-scale survey data, such as the National Family Health Survey (NFHS), which does not permit analysis at the local neighborhood level. On the tea estates, divisions are set up as neighborhoods, with workers' families living adjacent to one another in rows of company housing known as "labor lines." Divisions are separated from one another by several miles over very hilly terrain, and thus their boundaries are quite clear. ${ }^{3}$ Although workers may have relatives in other areas of the tea estates, social interaction between the divisions is limited. Travel to work, school, and health facilities within the division is by foot, and trips between estates and to the central town are organized by private jeep service. Given the long distances, contacts outside the division are restricted to occasional shopping trips,

\footnotetext{
${ }^{3}$ This solves another common problem, which is defining a neighborhood and its appropriate boundaries. This problem is particularly severe for researchers who use artificial administrative boundaries, such as census tracks (Sampson, Morenoff, and Gannon-Rowley 2002; Stephenson and Tsui 2002; Montgomery and Hewitt 2005; Sastry et al. 2006).
} 
holidays, and shared ceremonies, such as marriages. Therefore, the most frequent and relevant social interactions that affect child health are likely to occur within divisions.

Second, a major issue in the neighborhoods effects research is unobserved heterogeneity. Neighborhoods are dynamic, and individuals move into or out of them in response to perceived or real differences in social services, amenities, or neighborhood composition (Jackson and Mare 2007). Thus, a community effect could merely proxy for unobserved characteristics of individuals who self-select into the neighborhood, indicating a spurious relationship between neighborhood effects and health outcomes (Pebley, Goldman, and Rodriguez 1996; Sampson, Morenoff, and Gannon-Rowley 2002; Sastry et al. 2006; Luke and Munshi 2007). For example, Parashar (2005) found that the higher proportion of literate females within a district is associated with improved immunization of children in India. The neighborhood effect could indicate social processes or social learning for the average women in the district regardless of her individual educational attainment or literacy (the causal community effect), or it could reflect characteristics of women that are correlated with beneficial health outcomes but are not measured in the data (unobserved heterogeneity).

The ideal research scenario would be to assign individuals randomly across neighborhoods (and thus irrespective of caste, race, or other individual characteristics) and to prohibit residential change (Acevedo-Garcia and Osypuk 2008). In the tea estates, family settlement was completed more than 70 years ago, and because workers cannot move across divisions except through marriage, the original patterns of family and caste groupings across divisions largely remain in place today. Families cannot choose to re-sort based on social, economic, or structural changes that have taken place across divisions in recent decades. For example, women who would otherwise foster healthy outcomes for their children cannot easily relocate into divisions where women are more highly educated or literate on average. Furthermore, the distribution of castes across divisions is, in some senses, arbitrary. In contrast to rural India, where caste groups are extremely segregated within the village, small clusters of families originally settled together on the tea estates, and these groups were dispersed amongst other castes within divisions. In our analysis, we control for sub-caste affiliation to capture any remaining caste differences, and thus isolate neighborhood effects that could influence child health outcomes on the tea estates.

An important unobserved characteristic related to health outcomes is socioeconomic status. In India, caste (and neighborhood) continues to be associated with socioeconomic class, despite government programs aimed at alleviating historical disadvantages by subsidizing education and reserving positions in institutions of higher learning and the public sector for the lower castes (Parashar 2005; Dommaraju, Agadjanian, and Yabiku 2008). Thus, the caste or neighborhood effects identified in multiple studies may not accurately reflect social interactions and shared beliefs and 
practices (the causal community effect), but may instead be proxies for differential socioeconomic status across communities. Many researchers attempt to control for differences in socioeconomic status using available survey measures; however, they cannot account for all unobserved factors related to socioeconomic conditions. In contrast to workers in much of rural and urban India today, workers who live on the tea estates have the same economic opportunities and are assigned to the same jobs (by sex) regardless of caste or other individual characteristics. This structure also translates into income equality across castes (Luke and Munshi 2011). ${ }^{4}$ In addition, lower castes have higher levels of education than higher caste groups on the estates (Luke and Munshi 2011), which is the opposite of the usual pattern in India. Thus, the setting allows us to essentially control for the usual differences in education and income that exist across castes and that continue to produce health disparities in rural India.

The labor structure also makes the tea estates a particularly interesting context in which to study the effect of women's employment on child outcomes. In contrast to the labor market in much of rural India, women are the primary workforce on the tea estates and have full-time employment over their lifetimes. They work as tea-leaf pluckers and are paid at a piece rate (by weight of leaves plucked). Men are involved in supporting tasks, such as weeding and pruning, or in the estate tea factories, and these jobs are remunerated at a fixed rate. In addition, many husbands are unemployed. Therefore, women's incomes are likely to reach high levels relative to the earnings of women in many parts of rural India; and, on average, women earn more than their husbands on the tea estates. Theories of household decision-making hold that increases in the income of women relative to that of their husbands are associated with increased bargaining power within the household (Behrman 1988; Xu and Lai 2002). The high proportionate income of women on the tea estates could lead them to assert and achieve their preferences for investing in child health (Luke and Munshi 2011).

Finally, it is often the case that community effects-such as those found at the district level - reveal differential access to health and welfare services and do not identify social processes at work across individuals in the local community (Montgomery and Hewitt 2005; Dommaraju, Agadjanian, and Yabiku 2008; Linnemayr, Alderman, and Ka 2008). On the tea estates, most services are standardized across individuals and households under the 1951 Plantation Labor Act. Housing, water and sanitation, health services, and educational facilities up to primary school are of relatively high quality and are offered free of charge to estate workers and their families. The maternal and child health program includes the assistance of trained health professionals at all deliveries, as well as prenatal and antenatal care. With respect to child nutrition, an intensive monitoring and intervention program operates across all

\footnotetext{
${ }^{4}$ This also reflects the fact that particular caste groups have not been able to self-select into particularly advantageous estates in terms of income differentials.
} 
estates. These efforts to provide high-quality health services for all are reflected in positive child outcomes: infant mortality was 19 per 1,000 in 1999-2000 on the tea estates (Tata Tea 2000) compared to 48 for Tamil Nadu, the state from which the workers originated, and 68 for the entire country in 1998-99 (IIPS and Macro ORC 2000). In sum, the unique features of the tea estates allow us to control to some extent for unobserved heterogeneity and socioeconomic and structural differences that persist across castes (and individuals) in rural India today.

\section{Previous research on the correlates of child health}

\subsection{Community-level effects}

Previous research has identified multiple pathways through which neighborhood effects operate to influence health outcomes. Much of the extant literature has examined the role of socioeconomic status of the community independent of individual and household characteristics. Measures such as neighborhood poverty, average living standards among households, and housing conditions have been linked to a variety of mortality and morbidity outcomes, including self-reported health status, adult mortality and homicide, cancer, heart disease, and unsafe sexual behavior (Malmstrom, Sundquist, and Johansson 1999; Kapral et al. 2002; Sampson, Morenoff, and GannonRowley 2002; O'Malley et al. 2003; Horne et al. 2004) as well as birth weight and child health and mortality (Das Gupta 1997; Yen and Syme 1999; Montgomery and Hewett 2005; Schempf, Strobino, and O'Campo 2009). Neighborhood poverty and high levels of economic deprivation could signal the presence crime and social disorder (Do et al. 2008) or a shortage of the material and social resources necessary to sustain basic institutions, such as schools, services, or housing conditions (Shin 2007; Rosenbaum 2008). The level of education within the community has also been found to be an important correlate of maternal and child health (Parashar 2005; Messer et al. 2008; Moestue and Huttly 2008). Educated mothers or other educated individuals residing in the local area may have useful knowledge about the prevention and treatment of disease, or they may exhibit healthy behaviors, such as breastfeeding or other feeding practices, which could be imitated by parents (Das Gupta 1987; Kravdal 2004; Parashar 2005). Community-level education is often measured by maternal schooling, but a similar pathway could operate for paternal education (Kravdal 2004).

There is emerging evidence that the level of women's empowerment within the local community can influence health behaviors, including fertility preferences, contraceptive use, and domestic violence (Koenig et al. 2003; Moursund and Kravdal 2003). Increases in women's autonomy and decision-making in the aggregate could 
reinforce changes in gender norms or increase female solidarity (Koenig et al. 2003), which could in turn empower individual women to undertake beneficial actions relating to child health. Women's empowerment at the community level is operationalized in various ways in the literature, including in the form of women's economic contributions, such as income or participation in savings or credit groups or, more directly, as decision-making power over various domains within the household (Koenig et al. 2003; Moursund and Kravdal 2003).

\subsection{Individual- and family-level effects}

Our statistical analysis incorporates numerous individual- (child-) and family-level measures found to influence birth weight and child nutritional status in previous studies. With respect to children's characteristics, research has found a positive association between birth order and birth weight (Côté, Blanchard, and Lalmière 2003) and a negative association between birth order and nutritional status, based on the assumption that first-borns receive the highest doses of parental attention post-birth (Rajaram, Sunil, and Zottarelli 2003). The sex of the child has also been linked to health outcomes. A persistent cultural issue in South and East Asia is son preference, which is manifested in fewer health investments and higher mortality for girls relative to boys (Chen, Huq, and D'Souza 1981; Das Gupta 1987; Behrman 1988; Miller 1997; Pal 1999; Hotchkiss, Mock, and Seiber 2002). While son preference has historically been greatest in North India, there is emerging evidence of increased son preference accompanying the transition to low fertility in South India (Basu 1999; DiamondSmith, Luke, and McGarvey 2008).

There is a vast body of literature on the effect of maternal education on child health outcomes (e.g., Kandala, Magadi, and Madise 2006; Linnemayr, Alderman, and $\mathrm{Ka}$ 2008). While the association is generally positive across contexts, including for child nutritional status (Rajaram, Zottarelli, and Sunil 2007), the pathways by which maternal education operates are less well understood. Researchers believe that maternal education could reflect greater knowledge about disease and healthy practices, or the autonomy to make decisions regarding child well-being within the household or health care setting (Caldwell 1986; Bicego and Boerma 1993; Desai and Jain 1994; Shin 2007). ${ }^{5}$ Maternal education could also proxy for women's own health and nutritional status (Sakar and Saikia 2000; Shin 2007). Previous research has also found that paternal education is positively associated with child health and nutritional status

\footnotetext{
${ }^{5}$ Several recent studies have found a positive effect of mothers' nutrition knowledge on child nutritional status outcomes independent of maternal education (Webb and Block 2004; Burchi 2010).
} 
(Rajaram, Sunil, and Zottarelli 2003; Webb and Block 2004; Kandala, Magadi, and Madise 2006; Linnemayr, Alderman, and Ka 2008; Moestue and Huttly 2008).

Household economic status can determine investments in child health, and research has found that lower status is generally associated with poorer outcomes (Rajaram, Sunil, and Zottarelli 2003; Rajaram, Zottarelli, and Sunil 2007; Pradhan and Arokiasamy 2006). In addition to household wealth, the economic resources of individual parents are important correlates of child health. In particular, parental employment and income are commonly used measures of individual bargaining power within the household (Xu and Lai 2002), and a range of studies have found a positive effect of women's income on child health and education (Behrman 1988; Thomas 1990; Haddad and Hoddinott 1994; Luke and Munshi 2011). ${ }^{6}$

\section{Data and methods}

To create a dataset of individual-, family-, and community-level variables, we merged three different sources of data from the tea estates. First, information on child health was collected from estate records during Phase 1 of our fieldwork in March 2002. Each estate hospital records weights at birth. Each division maintains a crèche staffed with trained attendants for all children ages five and under, which is free of charge. Each child's "weight for age," which is a measure of both acute and chronic malnutrition (Griffiths, Matthews, and Hinde 2002), is recorded monthly in the crèche. Medical personnel in the estate hospital subsequently convert this information into a Z-score, which is the difference (expressed in standard deviations) of a child's weight for age from the median weight of children of the same age and sex in the well-nourished international reference population (WHO 1995, 2006; de Onis and Blössner 1997). By conventional definitions, children between one and two standard deviations below the reference median are categorized as having slight malnutrition, those between two and three standard deviations below the median are determined to have moderate malnutrition, and those more than three standard deviations below the median are categorized as suffering from severe malnutrition (de Onis and Blössner 1997). On the tea estates, if a child is found to have any degree of malnourishment in a given month, the family is counseled on feeding practices, and the child is given a nutritional

\footnotetext{
${ }^{6}$ Other studies have found that women's labor force participation negatively affects child health, perhaps because working women have less time to devote to caretaking or they decrease breastfeeding. The effects are often mediated if there is a comparable caretaker for the child in the household (Desai and Jain 1994; Sivakami 1997). On the tea estates, all children ages five and under are taken to a crèche when mothers are working, so they receive standardized, high-quality child care (see Section 4 for more details on child services on the tea estates).
} 
supplement during the daily lunch meal in the crèche. For every child age 10 and under in March 2002, we collected information from health records on the weight-for-age Zscore category $(0,-1,-2$, or -3$)$ at the exact ages of one to five, as well as information on birth weight, birth order, and sex. ${ }^{7}$

Second, during Phase 1 of our fieldwork, we also obtained information from the tea company's computerized records on yearly wages from 1997-2001 for all workers. Third, in Phase 2 of fieldwork in January to March 2003, our research team conducted a survey of a random sample of 3,700 married female tea plantation workers. The survey collected information on the demographic characteristics of the women and of their husbands and children.

For the present analysis, child characteristics and outcomes in each calendar year 1997-2002 were matched with their mothers' and fathers' income for those years, as well as with survey data on mother's age at child's birth, caste, and parental schooling. Because we did not have information on parental income for 2002, we assigned children their mothers' and fathers' income in 2001. Overall, the children in the sample ranged from age zero to six in 2002. The final sample of children for the analysis of birth weight was 638 , and there were 691 observations for the analysis of weight for age at age one. ${ }^{8}$

\subsection{Dependent variables}

Table 1 reports the percentages of children from 1997-2002 with low birth weight and malnutrition based on a low weight for age at age one. Birth weight was recorded in kilograms, and a dichotomous measure was constructed, with low birth weight $(<2.5$ kilos [WHOSIS 2008]) coded one, and zero otherwise. Approximately one-quarter $(24.29 \%)$ of the children in the sample had low birth weight. Low weight for age is a dichotomous variable coded one for yes and zero for no. Few children experienced moderate $(5.07 \%)$ or severe malnutrition $(0.58 \%)$, for a total of $5.65 \%$. This compares to a national prevalence of $49.4 \%$ for rural Indian children (Rajaram, Zottarelli, and Sunil 2007). Because the prevalence of malnutrition at this level is so low on the tea estates, we collapsed the three categories of malnutrition into one category of low

\footnotetext{
${ }^{7}$ Previous studies have examined community effects on other child health outcomes, including immunizations (Pande 2003; Parashar 2005). We did not record child immunization status, as almost all children are routinely vaccinated on the tea estates due to close follow-up by medical staff, which results in little variation in coverage.

${ }^{8}$ There is a larger sample size for children at age one because children born in 1996 were not included in the birth weight sample, but they were included in the nutritional status at age one sample (they were age one in 1997).
} 
weight for age. Thus, in our sample, $40.38 \%$ of children were slightly, moderately, or severely malnourished at age one.

Table 1: Child health indicators in South Indian tea estates, 1997-2002

\begin{tabular}{lcc}
\hline & Frequency & Percent \\
\hline Low birth weight $(<2.5 \mathrm{~kg})$ & 155 & 24.29 \\
$\mathrm{~N}$ & 638 & \\
Weight for age at age 1 & & \\
Normal $(-1<\mathrm{Z}$ score $<=0)$ & 412 & 59.62 \\
Slight malnutrition $(-2<Z$ score $<=-1)$ & 240 & 34.73 \\
Moderate malnutrition $(-3<Z$ score $<=-2)$ & 35 & 5.07 \\
Severe malnutrition $(Z$ score $<=-3)$ & 4 & 0.58 \\
$\mathrm{~N}$ & 691 & \\
\hline
\end{tabular}

\subsection{Independent Variables}

Descriptive statistics for the independent variables are presented in Table 2. The childspecific variables include sex, birth order, and current age in 2002. The latter variable controls for period effects, such as environmental conditions that may fluctuate from year to year. Family-level variables include the mother's age, the highest year of completed schooling for women and their husbands, women's income, total household income, and the mother's sub-caste. ${ }^{9}$ Mother's age is time-varying and corresponds to the year of child birth or age one. Maternal and paternal education were both measured at the time of the survey in 2003. While educational attainment levels could change over time, they are likely to have been completed before the commencement of childbearing.

\footnotetext{
${ }^{9}$ There is very little intermarriage across sub-castes in rural India, including on the tea estates. Therefore, mother's sub-caste is invariably the same as father's sub-caste.
} 
Table 2: $\quad$ Summary statistics for independent variables, 2002

\begin{tabular}{|c|c|c|c|c|}
\hline & Mean & SD & Min & Max \\
\hline \multicolumn{5}{|l|}{ Individual-level characteristics } \\
\hline Age (years) & 3.44 & 1.53 & 0.00 & 6.00 \\
\hline Male & 0.50 & 0.50 & 0.00 & 1.00 \\
\hline Birth order & 1.97 & 0.94 & 1.00 & 11.00 \\
\hline \multicolumn{5}{|l|}{ Family-level characteristics } \\
\hline Mother's age (years) & 28.77 & 4.18 & 20.00 & 47.00 \\
\hline Mother's years of schooling ${ }^{a}$ & 5.41 & 3.28 & 0.00 & 12.00 \\
\hline Father's years of schooling ${ }^{a}$ & 6.54 & 2.80 & 0.00 & 13.00 \\
\hline Mother's income (Rs. 1000) ${ }^{b}$ & 19.89 & 5.33 & 0.00 & 31.83 \\
\hline Household income (Rs. 1000) & 39.92 & 9.18 & 1.11 & 64.26 \\
\hline \multicolumn{5}{|l|}{ Sub-caste } \\
\hline Thevar & 0.11 & 0.32 & 0.00 & 1.00 \\
\hline Sakliyar & 0.05 & 0.23 & 0.00 & 1.00 \\
\hline Pallar & 0.41 & 0.49 & 0.00 & 1.00 \\
\hline Paraiyar & 0.29 & 0.45 & 0.00 & 1.00 \\
\hline Other & 0.13 & 0.34 & 0.00 & 1.00 \\
\hline \multicolumn{5}{|l|}{ Division-level characteristics } \\
\hline Women's mean years of schooling ${ }^{a}$ & 3.66 & 0.69 & 1.79 & 5.39 \\
\hline Men's mean years of schooling ${ }^{a}$ & 5.83 & 0.65 & 4.32 & 7.46 \\
\hline Mean women's income (Rs. 1000) & 23.05 & 1.33 & 19.90 & 26.66 \\
\hline Mean household income (Rs. 1000) ${ }^{b}$ & 41.40 & 3.42 & 32.43 & 52.73 \\
\hline$N=691$ & & & & \\
\hline
\end{tabular}

Notes: ${ }^{a}$ Measured in $2003,{ }^{b}$ Measured in 2001

Mother's income and total household income are time-varying and correspond to the year of child birth or age one. Household income is the sum of the spouses' earnings, and both income variables are divided by Rs. 1000 in the analysis. ${ }^{10}$ Most surveys, including the NFHS, do not record individual or household income, as it is difficult to collect accurate information (Parashar 2005). This is particularly true for women in many developing country settings, who are often engaged in activities outside of the formal labor force, and their economic contributions to the household are difficult to quantify (Korinek 2004). On the tea estates, the primary occupation of each worker is known, and we have very accurate data on income from the company's computerized records. In the full sample, women on the tea estates were found earn over one-half of total household income on average (Luke and Munshi 2011) a percentage unlikely to be replicated in many developing or developed country

\footnotetext{
${ }^{10}$ In the final sample, one woman was recorded as earning zero income in 2001 (although she had non-zero values for 1997-2000), perhaps due to illness or injury. We retain this observation in the sample.
} 
settings. In our analytical sample of young children, their mothers were shown to earn slightly less than $50 \%$ of the total household income.

Most surveys in India, including the NFHS, do not collect information on specific sub-caste affiliations, and instead record broad caste categories, including scheduled castes (the designation of the lowest caste groups), other backward castes, and the remaining forward (or higher) caste groups. In the survey of female tea workers, women reported their sub-caste by name, and we subsequently coded these into the five major sub-caste groups on the estates, including Thevar (warrior caste), Sakliyar (laborer caste), Pallar and Paraiyar (former slave castes), and a residual category including all smaller groups. Sakliyars, Pallars, and Paraiyars are scheduled castes according to the government designation, and represent approximately three-quarters of the children in our sample. Thevar is a forward caste $(12 \%)$, and the remaining smaller groups are designated as other backward castes (14\%).

Finally, to examine the role of local social processes, we included four divisionlevel variables aggregated from individual measures. These variables were constructed by using information from the full survey sample of 3,700 women, and were not limited to the mothers' and fathers' information from the smaller child sample. Nevertheless, because there were relatively few observations per division, these measures were constructed using non-self means, whereby individual observations were dropped when calculating a respondent's own division-level values (Christiaensen and Alderman 2004). This was done to reduce the correlation between individual- and communitylevel variables. We included a time-varying measure of community-level economic status, which was calculated as the mean household income within each division, and a time-varying community-level measure of the mean women's income per division. We also created variables for the mean years of schooling of women, and the mean years of schooling of husbands in each division.

\subsection{Analytical strategy}

We used a multilevel random intercept logistic model with children (Level 1) nested within divisions (Level 2) to estimate the probability of low birth weight and low weight for age at age one. In this study, children were sampled from 77 divisions. We expected to find that the health statuses of children within the same division are correlated, as they are likely to share community socioeconomic characteristics, environmental exposure, and social processes. Multilevel models allowed us to assess the effects of hierarchical covariates measured at different levels on our outcomes (Monda et al. 2007). Multilevel models also corrected for biases in parameter estimates and standard errors by adjusting intra-group correlations due to within-division 
clustering of the data (Guo and Zhao 2000; Rabe-Hesketh and Skrondal 2008). Without such a correction, statistical significance is likely to be inflated.

The unobserved heterogeneity that results in similar outcomes among children from the same divisions can be captured by allowing the division-level intercept to vary across different divisions. That is, those from the same division share the same deviation from the population-averaged intercept among all children, leading to division-specific intercepts. Unlike a fixed-effects model, in which a division-specific intercept is estimated for all divisions, a random-effects model allows us to treat the division-specific intercepts as random. We therefore only needed to estimate the variance of the random intercepts. A significant variance of the random intercepts indicates the presence of unobserved factors that explain the intra-division correlation.

Previous studies have found that the nutritional statuses of children tend to be correlated within the same family in India (Das Gupta 1997; Griffiths, Matthews, and Hinde 2002) and Malawi (Madise and Mpoma 1997). In our sample, 37\% of the children were clustered within families. In our exploratory analysis (results not shown here), we fitted three-level random intercept models, with family as Level 2 and division as Level 3. The coefficients of the random effects at the family level were not found to be significant, which suggests that there is no intra-family correlation due to unobserved characteristics. As a result, we ignored family-level clustering in our models.

In the analysis, our first aim was to determine whether neighborhood effects exist independent of caste and other individual- and family-level characteristics, and our second aim was to explore the pathways through which these effects could be operating. Therefore, for each outcome, we examined two specifications. Model 1 included individual- and family-level characteristics (including sub-caste categories) only, and we determined whether the division-level variance is statistically significant. In Model 2 , we added the four division-level variables. When estimating the probability of low weight for age at age one, we included a third model that adds a variable for low birth weight of the child as a control. In addition to the direct effect of birth weight on children's weight one year later, some of the independent variables considered here could be associated with low birth weight and malnutrition at age one. Therefore, controlling for low birth weight helped us to differentiate between its direct effects on malnutrition and the indirect effects that operate through low birth weight. All of the regressions were fitted using the Generalized Linear Latent and Mixed Models (GLLAMM) procedure in Stata, which provides a maximum likelihood framework for models with unobserved components (latent variables), including multilevel models (Rabe-Hesketh and Skrondal 2008). 


\section{Results}

Table 3 presents the results from random-effects logit regressions for low birth weight. Model 1 includes individual- and family-level variables. All of the statistically significant effects that we estimated for low birth weight were found to be significant at the 10-percent level. The risk of low birth weight is significantly lower for male children than for females, which is the opposite of our expectations. Higher birth order and father's years of schooling are significantly related to a reduced risk of low birth weight. With respect to caste, we found that the children of other caste groups and of the Pariyars are significantly less likely to experience low birth weight than the reference category, Thevars, which is a forward caste. This result also runs counter to most existing research on caste differences in child health. There were no statistically significant random effects in the model, which indicates that there were no unobserved division-level factors that affected the risk of low birth weight. Thus, after controlling for caste and other correlates of low birth weight, we found that no significant neighborhood effects remained.

Model 2 added division-level variables related to socioeconomic processes within the local community. None of these variables was shown to be significantly associated with the risk of low birth weight. The individual- and family-level characteristics maintained similar magnitudes and levels of significance across both models. The variance of the division-level random intercepts in Model 2 were not found to be significant.

Table 4 presents the results of the analysis of malnutrition measured by low weight for age at age one. All of the significant results in these models were found to be significant at the five-percent level, unless otherwise noted. In Model 1, we found a significant sex difference in favor of male children. Both maternal education and income displayed significant protective effects against malnutrition. We also found that none of the caste categories are significantly different from Thevars, the reference group. Finally, we found highly significant random effects in the model, which suggests that there are unobserved division-level factors that affect the risk of malnutrition at age one. 
Table 3: Two-level random-effects logistic regression estimates for low birth weight

\begin{tabular}{|c|c|c|c|c|c|c|}
\hline & \multicolumn{3}{|c|}{ Model 1} & \multicolumn{3}{|c|}{ Model 2} \\
\hline & Coef. & Std. Err. & $P>z$ & Coef. & Std. Err. & $\mathbf{P}>\mathbf{z}$ \\
\hline \multicolumn{7}{|l|}{ Individual-level characteristics } \\
\hline Age (years) in 2002 & -0.05 & 0.08 & & 0.01 & 0.14 & \\
\hline Male & -0.38 & 0.20 & + & -0.38 & 0.20 & + \\
\hline Birth order & -0.22 & 0.12 & + & -0.23 & 0.12 & + \\
\hline \multicolumn{7}{|l|}{ Family-level characteristics } \\
\hline Mother's age (years) at child's birth & 0.003 & 0.03 & & 0.01 & 0.03 & \\
\hline Mother's years of schooling & -0.05 & 0.03 & & -0.05 & 0.03 & \\
\hline Father's years of schooling & -0.07 & 0.04 & + & -0.07 & 0.04 & + \\
\hline Mother's income (Rs. 1000) & -0.04 & 0.03 & & -0.04 & 0.03 & \\
\hline Household income (Rs. 1000) & 0.02 & 0.02 & & 0.02 & 0.02 & \\
\hline \multicolumn{7}{|l|}{ Sub-caste (reference: Thevar) } \\
\hline Sakliyar & -0.24 & 0.48 & & -0.35 & 0.50 & \\
\hline Pallar & -0.49 & 0.32 & & -0.54 & 0.32 & + \\
\hline Paraiyar & -0.63 & 0.34 & + & -0.62 & 0.34 & + \\
\hline Other & -0.65 & 0.39 & + & -0.74 & 0.40 & + \\
\hline \multicolumn{7}{|l|}{ Division-level characteristics } \\
\hline Women's mean years of schooling & -- & -- & & 0.13 & 0.21 & \\
\hline Men's mean years of schooling & -- & -- & & -0.07 & 0.21 & \\
\hline Mean women's income (Rs. 1000) & -- & -- & & -0.03 & 0.12 & \\
\hline Mean household income (Rs. 1000) & -- & -- & & 0.04 & 0.06 & \\
\hline Constant & 0.53 & 0.94 & & -0.59 & 2.38 & \\
\hline$\sigma^{2}$ & 0.30 & 0.19 & & 0.29 & 0.19 & \\
\hline Within-division correlation & 0.08 & & & 0.08 & & \\
\hline Log likelihood & -339.59 & & & -338.85 & & \\
\hline $\mathrm{N}$ & 638 & & & 638 & & \\
\hline
\end{tabular}

Note: $\sigma^{2}=$ variance of division-level random intercept; $+p<0.1 ;{ }^{*} p<0.05 ;{ }^{* \star} p<0.01 ;{ }^{* \star \star} p<0.001$.

Division-level variables were added to Model 2. We found that the child's current age significantly increases the risk of malnutrition at age one, which suggests that the nutritional status of children on the tea estates is improving over time. The other individual- and family-level characteristics generally maintained similar magnitudes and levels of significance across both models. With respect to the division-level variables, children living in divisions with higher mean years of women's schooling were found to be at significantly lower risk of malnutrition. This effect is quite large: for every additional year in mean women's schooling, the likelihood of low weight for age decreases by approximately $40 \%$. Finally, we found highly significant divisionlevel random effects in Model 2, which indicates that unobserved neighborhood effects remain unaccounted for. ${ }^{11}$

\footnotetext{
${ }^{11}$ We also experimented with interactions between the sex of the child and caste and division-level variables, and found no significant results.
} 
Table 4: Two-level random-effects logistic regression estimates for low weight for age at age one

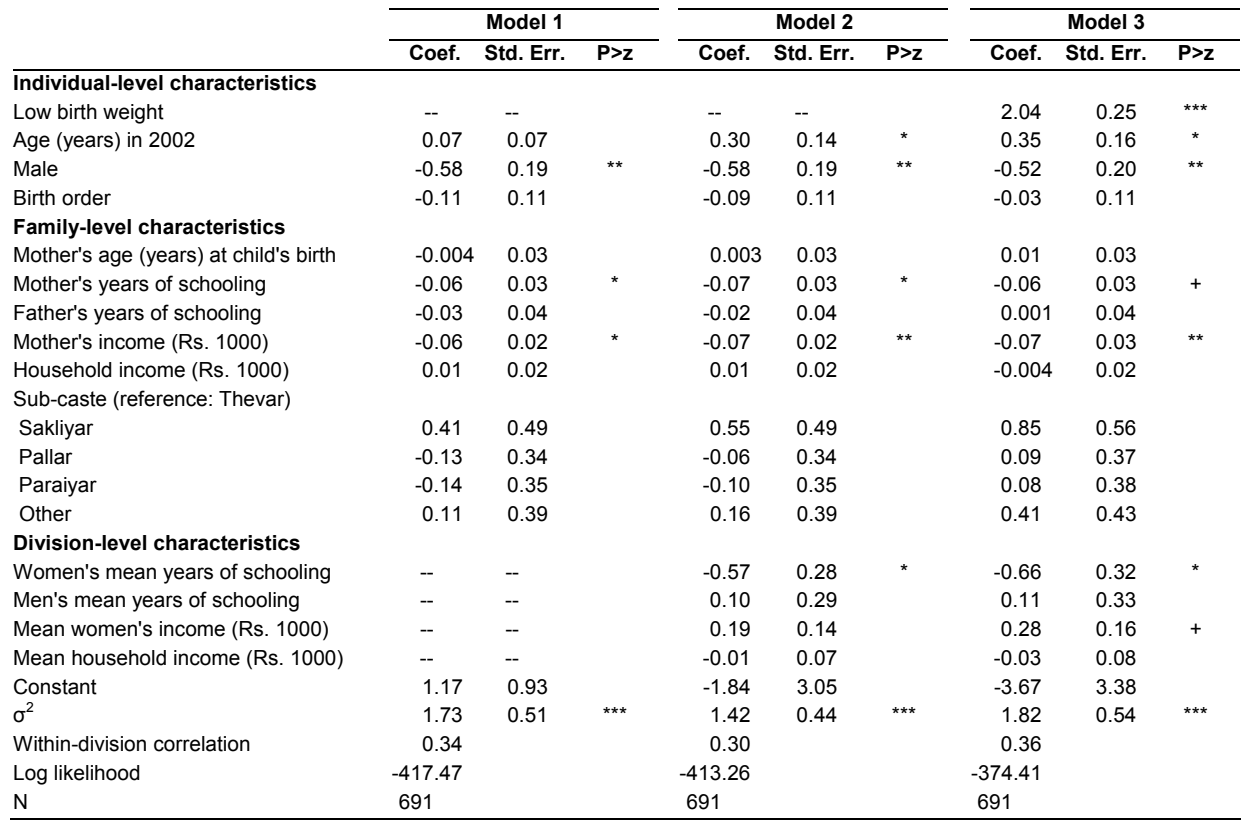

Note: $\sigma^{2}=$ variance of division-level random intercept; $+p<0.1 ;{ }^{*} p<0.05 ;{ }^{\star \star} p<0.01 ;{ }^{* \star} p<0.001$.

The low birth weight of the child was added as a predictor in Model 3, and it showed a positive and highly significant association with low weight for age at age one. The addition of this variable did not substantially attenuate any of the significant associations from Model 2, with the exception of women's education, which dropped to marginal significance. In addition, the positive coefficient on division-level women's income increased slightly and became marginally significant. This effect is in the unexpected direction, however. These results indicate that birth weight is not highly correlated with the observed individual- and family-level variables in our models. However, there are likely to be other omitted variables that determine both birth weight and malnutrition at age one, such as mothers' nutritional status. The fact that the coefficients on the independent variables in Model 2 remained generally stable in Model 3 suggests that these independent variables were also uncorrelated with any omitted variables that affect both outcomes, giving us some confidence that we have identified the direct effects of these factors on low weight for age at age one. The variance of the division-level random intercepts remained highly significant in Model 3. 


\section{Discussion and conclusions}

We explored the relationship between neighborhood context and child health outcomes on a group of tea estates in South India. Our first aim was to determine whether neighborhood effects on low birth weight and malnutrition exist, while our second aim was to explore the pathways through which these effects could be operating. Our analyses and findings make several important contributions to the literature on community effects and on child health in general, and to the study of these important topics in India in particular.

First, one of the major benefits of conducting a study on the tea estates is that the unique features of this context help us to go beyond other studies to isolate direct neighborhood effects on health. One problem with the study of community effects in India is that sub-castes generally live in distinct neighborhoods within rural villages, and it is therefore difficult to identify local residential (neighborhood) effects separately from relational (caste) effects. A second general research challenge is that community effects could proxy for unobserved characteristics correlated at the level of the community, particularly differences in socioeconomic status or access to health services, both of which are important predictors of health outcomes. A third and related difficulty is that individuals can self-select into certain neighborhoods, and thus their unobserved individual characteristics could once again be correlated within the same residential area. While individuals cannot generally choose specific neighborhoods in which to reside in rural Indian villages, the issue of selected movement is relevant to studies of community effects in most other research contexts.

The tea estates setting and our analytical strategy provide an opportunity to partially address these methodological challenges. With respect to unobserved heterogeneity, the research setting controls to some extent for self-selection into neighborhoods (conceived of as divisions on the tea estates), given that families from all caste groups were dispersed across divisions when they settled over three generations ago, and they have not been permitted to relocate to the divisions of their choice since that time. Furthermore, the research setting controls for economic opportunities, as well as for access to health services, due to the standardized jobs (by sex) and welfare services on the estates for all individuals regardless of caste. In addition, because caste groups are residentially integrated on the tea estates, this helps to solve the problem of caste and neighborhood being perfectly correlated, as is the case in rural Indian villages. Finally, in our regression analyses, we control for sub-caste categories that are more refined and that more closely reflect sub-caste networks than those usually used in research in India. The combined result of these conditions is that the division-level effects that we uncovered are likely to represent true neighborhood effects related to social interactions and processes. 
Our study also contributes to the emergent literature examining linkages between community effects and weight for age, as we found significant division-level effects for this measure of child malnutrition at age one. It appears that when caste groups are integrated, important neighborhood effects can arise that affect child health outcomes. We did not, in contrast, find significant division-level effects for low birth weight. It could be that weight at birth is an outcome that is affected to a lesser degree by neighborhood social interactions than is malnutrition, although new research in the U.S. has demonstrated that neighborhood resources and processes can shape maternal biological risk factors, such as nutritional status, thereby affecting birth weight (Schempf, Strobino, and O'Campo 2009). Alternatively, the comprehensive maternal care program provided on the tea estates could dampen division-level social influences that have an effect on birth weight in other contexts.

Our second contribution to the literature has been to ascertain specific pathways for the estimated neighborhood effects on malnutrition. We used aggregate measures of women's and men's schooling, women's income, and household income. Confirming previous research findings in India (Rajaram, Zottarelli, and Sunil 2007; Moestue and Huttly 2008), division-level women's education was shown to significantly decrease the risk of child malnutrition on the tea estates. Women's education appears to have important positive spillover effects on parents or other caregivers residing in close proximity, regardless of their own educational attainment, caste, or other characteristics. However, division-level income showed no association with malnutrition, as has been found in past studies (Shin 2007). Perhaps on the tea estates, where maternal and child health services are readily available, free, and of high quality, economic investments associated with neighborhood wealth have little impact on improvements in nutritional status.

We are also among the first to examine the connection between community-level women's empowerment and child health. Specifically, we found a negative (marginally significant) effect of women's income at the division level (controlling for divisionlevel household income) on child nutritional status, which runs counter to our expectations. One possible explanation for this finding is related to women's bargaining power within the division. Higher levels of female income are associated with women asserting their preferences within the household (Luke and Munshi 2011). Divisions with larger proportions of higher-earning women could experience a collective male backlash, with men attempting to reestablish their dominant position in the domestic sphere (Luke et al. 2007). In these divisions, women could be constrained from influencing important decisions relating to children's nutrition. Future research should continue to explore how women's empowerment at the community level affects child health outcomes. 
Our third contribution relates to the important individual- and family-level influences on low birth weight and malnutrition that we uncovered. Confirming past research, we found that maternal education and income have beneficial effects on the nutritional status of children. On the tea estates, women are often the primary breadwinners in their families, and individual income appears to translate into decisionmaking power with respect to children's health. Women's education and income could also proxy for other unobserved factors, such as women's health status on the tea estates. For example, because female workers are paid on a piece-rate basis (by weight of tea leaves plucked), women who pluck large amounts of leaves and have higher earnings are likely to be in good physical condition. ${ }^{12}$ We also found that fathers' schooling has a positive impact on birth weight. This effect could operate through behavioral mechanisms that affect mothers' nutritional intake or other practices during pregnancy. For example, more educated husbands may have the knowledge or influence to improve the nutritional status of their pregnant wives.

For both of the health outcomes that we investigated, we found significant effects in favor of male children. This is in line with the existing research regarding the young female disadvantage in nutritional status in South Asia (Hotchkiss, Mock, and Seiber 2002). However, there is some evidence that males are biologically prone to lower birth weight (Côté, Blanchard, and Lalmière 2003), so ours is an intriguing reverse result. As noted, birth weight could also be affected by maternal health behaviors during pregnancy. Given that ultrasound and other techniques to determine the sex of the fetus are common throughout India (Arnold, Kishor, and Roy 2002), it is possible that influential pre-birth behaviors are being modified depending on the sex of the child. Future research is warranted to explore the extent to which birth weight is another manifestation of son preference in India.

Finally, we found interesting results related to caste disparities in child health outcomes. We found no differences in malnutrition across sub-caste groups, and while significant differences were seen for low birth weight, the usual pattern found in most previous studies was reversed: several of the lower caste groups displayed better birth weight outcomes than the highest forward caste group. The specific structural characteristics of the estates - where economic opportunities and access to welfare services are standardized across castes - likely contributed to these findings. It appears that equalizing these important aspects has erased persistent caste disparities in child health found elsewhere in India. ${ }^{13}$

\footnotetext{
${ }^{12}$ Women's income is not associated with birth weight in Table 3, but it is associated with malnutrition in Table 4. This indicates that any omitted measure that determines both women's income and malnutrition must not be correlated with birth weight.

${ }^{13}$ The addition of sub-caste dummies in our regressions for low birth weight and malnutrition did not significantly improve the overall model fit (not shown), which provides further evidence that caste fails to serve as an important community hindrance to improved child outcomes on the tea estates.
} 
Several limitations to our study should be mentioned. First, although the tea estates setting helped us to identify neighborhood effects more directly than has been possible in most previous studies, it is not a perfect experimental setting. For example, individual families and sub-caste groups were not historically assigned randomly to residences in the divisions, and there continues to be some movement of individualsperhaps by choice - across divisions. Thus, there could be unobserved factors that are correlated with castes or divisions; if these factors also determine child health, then our estimates of the linkages between neighborhood effects and child health outcomes could be spurious.

The second limitation relates to the pathways by which we measured neighborhood effects. Although our study included measures of neighborhood socioeconomic status used in previous research (Sastry 1996; Hotchkiss, Mock, and Seiber 2002; Linnemayr, Alderman, and Ka 2008), our survey did not collect information on other neighborhood processes, such as collective efficacy, crime or victimization, participation in voluntary organizations, or specific health care knowledge (Sampson, Raudenbush, and Earls 1997; Browning and Cagney 2002; Wen, Cagney, and Christakis 2005; Schempf, Strobino, and O'Campo 2009; Stephenson 2009). These or other important social processes could be responsible for the divisionlevel variance in child malnutrition that remained unexplained in our models.

A third limitation is that our study did not include information on each woman's individual health or nutritional status - such as height, weight, or body mass - which have been shown to be important indicators of birth weight and child nutritional status (Sichieri, Taddei, and Everhart 2000; Rajaram, Zottarelli, and Sunil 2007; Schempf, Strobino, and O'Campo 2009). Maternal health status could reflect genetic endowments, health inputs in childhood, or a woman's current condition, all of which could directly affect children's health. We experimented with adding to our models several measures of women's illness experience that are available in the survey data, including any gynecological illness, injury, aches, or any other type of illness in the year before the survey (2002) (not shown). These variables were not found to be significant in any of the regressions for either outcome, and their addition did not change the coefficients or significance levels of the observed variables. While these results appear to suggest that women's health status is not a significant determinant of child health on the tea estates, these variables are self-reported, crude estimates of health conditions, and are unlikely to be perfect indicators of women's genetic endowments, childhood health conditions, or even current health and nutritional status. Other measures of women's health status remain unobserved, and these omitted variables could be correlated with observed measures of women's education or income 
or other factors (Shin 2007). Thus, without adequate controls for women's health status in our models, the effects of these proxies are likely to be inflated. ${ }^{14}$

A final comment pertains to our special research setting. Due to the unique features of the tea estates, our findings are not readily generalizable to South India or India as a whole. The historical residential and occupational integration of caste groups on the tea estates is an exceptional case in India. In addition, employment opportunities - especially for women-exceed those found in most rural areas of the country, and the provision of high-quality, affordable health services is not easily replicated beyond the plantation setting. Nevertheless, an exploration of community effects in a setting where caste groups have been historically integrated can shed some light on the potential for inter-caste interaction and its implications for fostering positive health outcomes in the future. Given recent trends of economic liberalization and increasing migration in India (Bhattacharyya and Korinek 2007; Bhagat and Mohanty 2009), caste groups could increasingly become residentially and occupationally integrated in metropolitan areas, where research on the role of both residential and relational types of community in solving urban health challenges is needed.

\section{Acknowledgements}

This project was directed by Nancy Luke and Kaivan Munshi, Brown University, and was funded by a grant from the National Institutes of Health (\#R01-HD046940) and the Harry Frank Guggenheim Foundation. Supplementary funding was provided by the Mellon Foundation and the University Research Foundation at the University of Pennsylvania. We wish to thank Homi Khusrokhan, as well as the management, staff, and workers of Tata Tea, Munnar, for their assistance and gracious hospitality during our extended stays on the tea estates. Binitha Thampi supervised the data collection and, together with Leena Abraham, assisted in the design of the survey. The authors wish to thank Margot Jackson, Shiva Halli, Kaivan Munshi, and participants at the 2009 IUSSP International Population Conference for their helpful comments on the paper.

\footnotetext{
${ }^{14}$ The addition of birth weight to Model 3 in Table 4 did not change the effects of the independent variables on malnutrition at age one substantially. This finding indicates that any omitted measure that determines malnutrition, including aspects of women's health status, must not affect birth weight.
} 


\section{References}

Abbott, E. and Luke, N. (Forthcoming). Local hierarchies and distributor (non)compliance: A case study of community-based distribution in rural North India. Health Care for Women International.

Acevedo-Garcia, D. and Osypuk, T.L. (2008). Invited commentary: Residential segregation and health - The complexity of modeling separate social contexts. American Journal of Epidemiology 168(11): 1255-1258. doi:10.1093/aje/kwn290.

Arnold, F., Kishor, S., and Roy, T.K. (2002). Sex-selective abortions in India. Population and Development Review 28(4): 759-785. doi:10.1111/j.17284457.2002.00759.x.

Basu, A.M. (1999). Fertility decline and increasing gender imbalance in India, including a possible Southern Indian turnaround. Development and Change 30(2): 237-263. doi:10.1111/1467-7660.00116.

Behrman, J.R. (1988). Intrahousehold allocation of nutrients in rural India: Are boys favored? Do parents exhibit inequality aversion? Oxford Economic Papers 40(1): 32-54.

Bhagat, R.B. and Mohanty, S. (2009). Emerging pattern of urbanization and the contribution of migration in urban growth in India. Asian Population Studies 5(1): 5-20. doi:10.1080/17441730902790024.

Bhattacharyya, S.K. and Korinek, K. (2007). Opportunities and vulnerabilities of female migrants in construction work in India. Asian and Pacific Migration Journal 16(4): 511-531.

Bicego, G.T. and Boerma, T. (1993). Maternal education and child survival: A comparative study of survey data from 17 countries. Social Science \& Medicine 36(9): 1207-1227. doi:10.1016/0277-9536(93)90241-U.

Bonu, S., Manju, R., and Baker, T.D. (2003). The impact of the National Polio Immunization Campaign on levels and equity in immunization coverage: Evidence from rural North India. Social Science \& Medicine 57(10): 1807-1819. doi:10.1016/S0277-9536(03)00056-X.

Browning, C.R. and Cagney, K.A. (2002). Neighborhood structural disadvantage, collective efficacy, and self-rated physical health in an urban setting. Journal of Health and Social Behavior 43(4): 383-399. doi:10.2307/3090233. 
Burchi, F. (2010). Child nutrition in Mozambique in 2003: The role of mother's schooling and nutrition knowledge. Economics and Human Biology 8(3): 331345. doi:10.1016/j.ehb.2010.05.010.

Caldwell, J.C. (1986). Routes to low mortality in poor countries. Population and Development Review 12(2): 171-220. doi:10.2307/1973108.

Chen, L.C., Huq, E., and D'Souza, S. (1981). Sex bias in the family allocation of food and health care in Rural Bangladesh. Population and Development Review 7(1): 55-70. doi:10.2307/1972764.

Christiaensen, L. and Alderman, H. (2004). Child malnutrition in Ethiopia: Can maternal knowledge augment the role of income? Economic Development and Cultural Change 52(2): 287-312. doi:10.1086/380822.

Cohen, D.A., Finch, B.K., Bower, A., and Sastry, N. (2006). Collective efficacy and obesity: The potential influence of social factors on health. Social Science \& Medicine 62(3): 769-778. doi:10.1016/j.socscimed.2005.06.033.

Cornish, F. and Ghosh, R. (2007). The necessary contradictions of 'community-led' health promotion: A case study of HIV prevention in an Indian red light district. Social Science \& Medicine 64(2): 496-507. doi:10.1016/ j.socscimed.2006.09.009.

Côté, K., Blanchard, R., and Lalmière, M.L. (2003). The influence of birth order on birth weight: Does the sex of preceding siblings matter? Journal of Biosocial Science 35(3): 455-462. doi:10.1017/S0021932003004553.

Das Gupta, M. (1987). Selective discrimination against female children in Rural Punjab, India. Population and Development Review 13(1): 77-100. doi:10.2307/1972121.

Das Gupta, M. (1997). Socio-economic status and clustering of child deaths in rural Punjab. Population Studies 51(2): 191-202. doi:10.1080/0032472031000149906.

de Onis, M. and Blössner, M. (1997). WHO Global Database on Child Growth and Malnutrition. Geneva: World Health Organization.

Desai, S. and Jain, D. (1994). Maternal employment and changes in family dynamics: The social context of women's work in rural South India. Population and Development Review 20(1): 115-136. doi:10.2307/2137632.

Diamond-Smith, N., Luke, N., and McGarvey, S. (2008). 'Too many girls, too much dowry': Son preference and daughter aversion in rural Tamil Nadu, India. 
Culture, Health and Sexuality 10(7): 697-708. doi:10.1080/ 13691050802061665.

Do, D.P., Finch, B.K., Basurto-Davila, R., Bird, C., Escarce, J., and Lurie, N. (2008). Does place explain racial health disparities? Quantifying the contribution of residential context to the Black/white health gap in the United States. Social Science \& Medicine 67(8): 1258-1268. doi:10.1016/j.socscimed.2008.06.018.

Dommaraju, P., Agadjanian, V., and Yabiku, S. (2008). The pervasive and persistent influence of caste on child mortality in India. Population Research and Policy Review 27(4): 477-495. doi:10.1007/s11113-008-9070-0.

Griffiths, P., Matthews, Z., and Hinde, A. (2002). Gender, family, and the nutritional status of children in three culturally contrasting states of India. Social Science \& Medicine 55(5): 775-790. doi:10.1016/S0277-9536(01)00202-7.

Guo, G., and Zhao, H. (2000). Multilevel modeling for binary data. Annual Review of Sociology 26: 441-462. doi:10.1146/annurev.soc.26.1.441.

Haddad, L. and Hoddinott, J. (1994). Women's income and boy-girl anthropometric status in Côte d'Ivoire. World Development 22(4): 543-553. doi:10.1016/0305750X(94)90110-4.

Hjejle, B. (1967). Slavery and agricultural bondage in South India in the nineteenth century. The Scandinavian Economic History Review XV(1,2): 71-126.

Horne, B.D., Muhlestein, J.B., Lappe, D.L., Renlund, D.G., Bair, T.L., Bunch, T.J., and Anderson, J.L. (2004). Less affluent area of residence and lesser-insured status predict an increased risk of death or myocardial infarction after angiographic diagnosis of coronary disease. Annals of Epidemiology 14(2): 143-150. doi:10.1016/S1047-2797(03)00125-X.

Hotchkiss, D.R., Mock, N.B., and Seiber, E.E. (2002). The effect of the health care supply environment on children's nutritional status in rural Nepal. Journal of Biosocial Science 34(2): 173-192. doi:10.1017/S0021932002001736.

International Institute for Population Sciences (IIPS) and ORC Macro (2000). National Family Health Survey (NFHS-2), 1998-99: India. Mumbai: IIPS.

Jackson, M.I. and Mare, R.D. (2007). Cross-sectional and longitudinal measurements of neighborhood experience and their effects on children. Social Science Research 36(2): 590-610. doi:10.1016/j.ssresearch.2007.02.002. 
Kandala, N.-B., Magadi, M.A., and Madise, N.J. (2006). An investigation of district spatial variations of childhood diarrhea and fever morbidity in Malawi. Social Science \& Medicine 62(5): 1138-1152. doi:10.1016/j.socscimed.2005.07.028.

Kapadia, K. (1995). Siva and Her Sisters: Gender, Caste, and Class in Rural South India. Boulder, CO: Westview Press.

Kapral, M.K., Wang, H., Mamdani, M., and Tu, J.V. (2002). Effects of socioeconomic status on treatment and mortality after stroke. Stroke 33(1): 268-275. doi:10.1161/hs0102.101169.

Koenig, M.A., Ahmed, S., Hossain, M.B., and Mozumder, A.M.B.K.A. (2003). Women's status and domestic violence in rural Bangladesh: Individual- and community-level effects. Demography 40(2): 269-288. doi:10.1353/ dem.2003.0014.

Korinek, K. (2004). Maternal employment during Northern Vietnam's era of market reform. Social Forces 83(2): 791-822. doi:10.1353/sof.2005.0015.

Kravdal, Ø. (2004). Child mortality in India: The community-level effect of education. Population Studies 58(2): 177-192. doi:10.1080/0032472042000213721.

Linnemayr, S., Alderman, H., and Ka, A. (2008). Determinants of malnutrition in Senegal: Individual, household, community variables, and their interaction. Economics and Human Biology 6(2): 252-263. doi:10.1016/j.ehb.2008.04.003.

Luke, N. and Munshi, K. (2007). Social affiliation and the demand for health services: Caste and child health in South India. Journal of Development Economics 83(2): 256-279. doi:10.1016/j.jdeveco.2006.07.005.

Luke, N. and Munshi, K. (2011). Women as agents of change: Female income and mobility in India. Journal of Development Economics 94(1): 1-17. doi:10.1016/j.jdeveco.2010.01.002.

Luke, N., Schuler, S.R., Mai, B.T.T., Thien, P.V., and Minh, T.H. (2007). Exploring couple attributes and attitudes and marital violence in Vietnam. Violence Against Women 13(1): 5-27. doi:10.1177/1077801206295112.

Madise, N.J. and Mpoma, M. (1997). Child malnutrition and feeding practices in Malawi. Food and Nutrition Bulletin 18(2): 190-201.

Malmstrom, M., Sundquist, J., and Johansson, S.-E. (1999). Neighborhood environment and self-reported health status: A multilevel analysis. American Journal of Public Health 89(8): 1181-1186. doi:10.2105/AJPH.89.8.1181. 
Messer, L.C., Viniloor, L.C., Laraia, B.A., Kaufman, J.S., Eyster, J., Holzman, C., Culhane, J., Elo, I., Burke, J.G., and O'Campo, P. (2008). Socioeconomic domains and associations with preterm birth. Social Science and Medicine 67(8): 1247-1257. doi:10.1016/j.socscimed.2008.06.009.

Miller, B.D. (1997). Social class, gender and intrahousehold food allocations to children in South Asia. Social Science \& Medicine 44(11): 1685-1695. doi:10.1016/S0277-9536(96)00371-1.

Milner, M.J. (1994). Status and Sacredness: A General Theory of Status Relations and an Analysis of Indian Culture. Cambridge, England: Cambridge University Press.

Moestue, H. and Huttly, S. (2008). Adult education and child nutrition: The role of family and community. Journal of Epidemiology and Community Health 62(2): 153-159. doi:10.1136/jech.2006.058578.

Monda, K.L., Gordon-Larsen, P., Stevens, J., and Popkin, B.M. (2007). China's transition: The effect of rapid urbanization on adult occupational physical activity. Social Science \& Medicine 64(4): 858-870. doi:10.1016/ j.socscimed.2006.10.019.

Montgomery, M.R. and Hewett, P.C. (2005). Urban poverty and health in developing countries: Household and neighborhood effects. Demography 42(3): 397-425. doi:10.1353/dem.2005.0020.

Moursund, A. and Kravdal, Ø. (2003). Individual and community effects of women's education and autonomy on contraceptive use in India. Population Studies 57(3): 285-302. doi:10.1080/0032472032000137817.

Munshi, K. and Rosenzweig, M. (2009). Why is mobility in India so low? Social insurance, inequality, and growth. Cambridge, Mass.: National Bureau of Economic Research (NBER Working Paper No. 14850).

Navaneetham, K. and Dharmalingam, A. (2002). Utilization of maternal health care services in Southern India. Social Science \& Medicine 55(10): 1849-1869. doi:10.1016/S0277-9536(01)00313-6.

O’Malley, C.D., Le, G.M., Glaser, S.L., Shema, S.J., and West, D.W. (2003). Socioeconomic status and breast carcinoma survival in four racial/ethnic groups: A population-based study. Cancer 97(5): 1303-1311. doi:10.1002/cncr.11160. 
Oakes, J.M. (2004). The (mis)estimation of neighborhood effects: Causal inference for a practicable social epidemiology. Social Science \& Medicine 58(10): 19291952. doi:10.1016/j.socscimed.2003.08.004.

Pal, S. (1999). An analysis of childhood malnutrition in rural India: Role of gender, income and other household characteristics. World Development 27(7): 11511171. doi:10.1016/S0305-750X(99)00048-0.

Pande, R.P. (2003). Selective gender differences in childhood nutrition and immunization in rural India: The role of siblings. Demography 40(3): 395-418. doi:10.1353/dem.2003.0029.

Parashar, S. (2005). Moving beyond the mother-child dyad: Women's education, child immunization, and the importance of context in rural India. Social Science \& Medicine 61(5): 989-1000. doi:10.1016/j.socscimed.2004.12.023.

Pebley, A.R., Goldman, N., and Rodriguez, G. (1996). Prenatal and delivery care and childhood immunization in Guatemala: Do family and community matter? Demography 33(2): 231-247. doi:10.2307/2061874.

Pradhan, J. and Arokiasamy, P. (2006). High infant and child mortality rates in Orissa: An assessment of major reasons. Population, Space and Place 12(3): 187-200. doi:10.1002/psp.408.

Rabe-Hesketh, S. and Skrondal, A. (2008). Multilevel and Longitudinal Modeling Using Stata $\left(2^{\text {nd }}\right.$ Edition). College Station, TX: Stata Press.

Rajaram, S., Sunil, T.S., and Zottarelli, L.K. (2003). An analysis of childhood malnutrition in Kerala and Goa. Journal of Biosocial Science 35(3): 335-351. doi:10.1017/S0021932003003353.

Rajaram, S., Zottarelli, L.K., and Sunil, T.S. (2007). Individual, household, programme and community effects on childhood malnutrition in rural India. Maternal and Child Nutrition 3(2): 129-140. doi:10.1111/j.1740-8709.2007.00086.x.

Rosenbaum, E. (2008). Racial/ethnic differences in asthma prevalence: The role of housing and neighborhood environments. Journal of Health and Social Behavior 49(2): 131-145. doi:10.1177/002214650804900202.

Rosenzweig, M.R. and Wolpin, K.I. (1986). Evaluating the effects of optimally distributed public programs: Child health and family planning interventions. American Economic Review 76(3): 470-482.

Sakar, N.C. and Saikia, A.C. (2000). Birth weight at Changlang, Arunachal Pradesh. Indian Journal of Pediatrics 67(6): 419-421. doi:10.1007/BF02859458. 
Sampson, R.J., Morenoff, J.D., and Gannon-Rowley, T. (2002). Assessing 'neighborhood effects': Social processes and new directions in research. American Review of Sociology 28: 443-478. doi:10.1146/annurev.soc.28.11060 1.141114 .

Sampson, R.J., Raudenbush, S.W., and Earls, F. (1997). Neighborhoods and violent crime: A multilevel study of collective efficacy. Science 277(5328): 918-924. doi:10.1126/science.277.5328.918.

Sastry, N. (1996). Community characteristics, individual and household attributes, and child survival in Brazil. Demography 33(2): 211-229. doi:10.2307/2061873.

Sastry, N., Ghosh-Dastidar, B., Adams, J., and Pebley, A.R. (2006). The design of a multilevel survey of children, families, and communities: The Los Angeles Family and Neighborhood Survey. Social Science Research 35(4): 1000-1024. doi:10.1016/j.ssresearch.2005.08.002.

Schempf, A., Strobino, D., and O'Campo, P. (2009). Neighborhood effect on birthweight: An exploration of psychosocial and behavioral pathways in Baltimore, 1995-1996. Social Science \& Medicine 68(1): 100-110. doi:10.1016/j.socscimed.2008.10.006.

Shin, H. (2007). Child health in Peru: Importance of regional variation and community effects on children's height and weight. Journal of Health and Social Behavior 48(4): 418-433. doi:10.1177/002214650704800406.

Sichieri, R., Taddei, J.A., and Everhart, J.E. (2000). Influence of parental height and sociodemographic factors on adolescent height in Brazil. Journal of Adolescent Health 26(6): 414-419. doi:10.1016/S1054-139X(99)00004-X.

Sivakami, M. (1997). Female work participation and child health: An investigation in rural Tamil Nadu, India. Health Transition Review 7: 21-32.

Som, S., Pal, M., Bhattacharya, B., Bharati, S., and Bharati, P. (2006). Socioeconomic differentials in nutritional status of children in the states of West Bengal and Assam, India. Journal of Biosocial Science 38(5): 625-642. doi:10.1017/S002 1932005026921.

Stephenson, R. (2009). Community influences on young people's sexual behavior in 3 African countries. American Journal of Public Health 99(1): 102-109. doi:10.2105/AJPH.2007.126904. 
Stephenson, R. and Tsui, A.O. (2002). Contextual influences on reproductive health service use in Uttar Pradesh, India. Studies in Family Planning 33(4): 309-320. doi:10.1111/j.1728-4465.2002.00309.x.

Subramanian, S.V. (2004). The relevance of multilevel statistical methods for identifying causal neighborhood effects. Social Science \& Medicine 58(10): 1961-1967. doi:10.1016/S0277-9536(03)00415-5.

Tata Tea (South India Division). (2000). Welfare Audit 1999-2000.

Thomas, D. (1990). Intra-household resource allocation: An inferential approach. Journal of Human Resources 25(4): 635-664. doi:10.2307/145670.

Webb, P. and Block, S. (2004). Nutrition information and formal schooling as inputs to child nutrition. Economic Development and Cultural Change 52(4): 801-820. doi:10.1086/420901.

Wen, M., Cagney, K.A., and Christakis, N.A. (2005). Effect of specific aspects of community social environment on the mortality of individuals diagnosed with serious illness. Social Science and Medicine 61(6): 1119-1134. doi:10.1016/j.soc scimed.2005.01.026.

World Health Organization (WHO) (1995). Physical status: The use and interpretation of anthropometry. Geneva: World Health Organization. (WHO Technical Report Series 854).

WHO Multicentre Growth Reference Study Group (WHO) (2006). WHO child growth standards: Length/height-for-age, weight-for-age, weight-for-length, weight-forheight and body mass index-for-age: Methods and development. Geneva: World Health Organization.

WHO Statistical Information System (WHOSIS) (2008). Indicator definitions and metadata, 2008. Geneva: World Health Organization. http://www.who.int/ whosis/indicators/compendium/2008/2bwn/en/index.html (July 24, 2010).

$\mathrm{Xu}, \mathrm{X}$. and Lai, S.-C. (2002). Resources, gender ideologies, and marital power: The case of Taiwan. Journal of Family Issues 23(2): 209-245. doi:10.1177/0192513 X02023002003.

Yen, I.H. and Syme, S.L. (1999). The social environment and health: A discussion of the epidemiologic literature. Annual Review of Public Health 20: 287-308. doi:10.1146/annurev.publhealth.20.1.287. 